\title{
LA PRESENCIA DE GALICIA EN LAS ÚLTIMAS REPRESENTACIONES DEL CICLO MÍTICO DE VALLE-INCLÁN (2000-2015)
}

\author{
THE PRESENCE OF GALICIA IN LAST PERFORMANCES OF VALLE \\ INCLAN'S MYTHICAL CYCLE PLAYS (2000- 2015)
}

Pablo Landín Martínez

UNED

pablolandin24@gmail.com

Fecha de Recepción: 11-02-2018

Fecha de Aceptación: 04-07-2018

RESUMEN:

El "ciclo mítico" de Valle-Inclán abarca cinco obras cuyo espacio común es una Galicia mítica como escenario ideal para la recreación de las pasiones e instintos más básicos de los personajes. El objetivo de este artículo es analizar la presencia de este espacio común en las puestas en escena de los primeros quince años del siglo XXI, en dos puntos concretos: la escenificación y la caracterización de los personajes.

Palabras Clave: Teatro. Representaciones. Ciclo mítico. Valle-Inclán. 2000- 2015

\section{AbSTRACT:}

The "Mythical Cycle" of Valle-Inclán includes five works whose common space is a mythical Galicia as the ideal setting for the recreation of the most basic passions and instincts of the characters. The objective of this article is to analyze the presence of this common space in the perfomances of the first fifteen years of the 21 st century, from two specific points: the staging and the characterization of the characters. 
KeY words: Theatre. Perfomances. Mythical Cycle. Valle-Inclán. 2000- 2015

\section{PREÁmbulo}

De las veintidós obras de teatro escritas por Valle-Inclán, cinco de ellas se enmarcan dentro del denominado ciclo mítico que tienen como espacio común Galicia, una Galicia mítica que su autor ideó como lugar propicio para que afloren las pasiones y los instintos más primitivos del ser humano ${ }^{1}$, pero que por otra parte, también recoge la esencia de la realidad gallega, lo que le ha servido para influir de materia notable en la literatura gallega:

Esa influencia es directísima en el caso de los autores gallegos que optaron por escribir en su lengua, porque nadie supo expresar como Valle, aunque en una lengua híbrida, las concepciones del mundo y el mundo del hombre gallego (Paz, Gago, 2000: 176).

Las cinco obras que constituyen el ciclo mítico son Águila de Blasón (1907), Romance de lobos (1908), El Embrujado (1913), Divinas palabras (1920), y Cara de plata (1923), obras que fueron publicadas en un periodo de tiempo que marca la transición del teatro de Valle-Inclán pero también una evolución de su idea de Galicia: mientras que las dos primeras Comedias (Águila de blasón y Romance de lobos) y El embrujado se encuadran dentro de un simbolismo que evocan la Galicia rural de la época de Valle-Inclán, las dos últimas obras, Divinas palabras y Cara de plata, son publicadas después de 1920, y muestran una Galicia más deformada y esperpéntica, a la vez que más crítica con esa sociedad.

Recientemente, estas cinco obras han sido llevadas a escena por diferentes directores ${ }^{2}$. El presente trabajo tiene por objeto de estudio aquellas representaciones del ciclo mítico

${ }^{1}$ Francisco Ruiz Ramón utiliza el término "mítico" con el significado de "vuelta al origen” (Ruiz Ramón, 2001: 95) en referencia a un mundo primitivo donde afloran con mayor intensidad las pasiones humanas. El ciclo lo componen cinco obras, cuyas fechas de publicación hacen referencia a cuando aparecieron publicadas como libros: Águila de Blasón. Comedia bárbara dividida en cinco jornadas (1907), Romance de lobos. Comedia bárbara dividida en tres jornadas (1908), El Embrujado. Tragedia de tierras de Salnés (1913), Divinas palabras. Tragedia de aldea (1920), y Cara de plata. Comedia bárbara (1923).

${ }^{2}$ Con la entrada de siglo, Calixto Bieito lleva a escena las Comedias bárbaras en inglés (Barbaric Comedies) con la compañía Abbey Theater, el Teatro Nacional de Dublin, en el Kings Theatre de Edimburgo los días 14 y 23 de agosto del 2000. También se representan en Alemania por la compañía Amateurtheater (2004); Águila de blasón dirigida por Maite Hernángómez (2006); El embrujado se representa conjuntamente con las otras piezas breves que conforman el Retablo de la avaricia, la lujuria y la muerte con la dirección de Alfonso Zurro en julio de 2005 en Girona; Divinas palabras es varias veces llevada a escena: en 2001 era dirigida por Montse Sala por la Compañía Cía, en una gira por Cataluña, y por Pablo Iglesias con la que se presentó en el Festival de Teatro de Cantabria 2001; más tarde la llevaron a escena Noelia Rosa (2006) y Deán Zayas (2006). A partir de 2007 se siguen representando las obras del ciclo mítico de Valle-Inclán: El embrujado, dirigida por María Jesús Hoyos, durante la temporada 2008-2009 por la Real Escuela Superior de Arte Dramático (RESAD); Martín Barreiro lleva a escena Romance de lobos en Argentina (2010); Divinas palabras sigue siendo la obra más representada dentro y fuera de España: Rodolfo García Vázquez (Brasil, 2007), Gustavo Bonamino (Argentina, 2009), la representación dirigida por Ricardo Iniesta (2009) que se trata de una reposición de la misma obra dirigida en 1998; Ricardo Camacho (Bogotá, 2010), Reda Hadadd (Polonia, 2011), A. Hermann (Suiza, 2012), y recientemente Pablo Ocaña con la compañía El Bardo la estrenada el 22 de marzo de 2013. 
que fueron estrenadas en España en estos primeros años del siglo XXI y que tuvieron cierta repercusión en los periódicos y revistas especializadas: Cara de plata dirigida por Etelvino Vázquez (2002), Comedias bárbaras de Bigas Luna (2003), Cara de plata de Ramón Simó (2005), Romance de lobos de Ángel Facio (2005), Divinas palabras de Gerardo Vera (2006), y Montenegro (Comedias bárbaras) dirigida por Ernesto Caballero (2013).

El objetivo de este trabajo es analizar la presencia de Galicia en estas representaciones a partir de las críticas publicadas en diferentes revistas y periódicos, y de los estudios de César Oliva (2007) y Paz Gago (2012) ${ }^{3}$, tanto en lo que se refiere al escenario como consecuentemente a la caracterización de los personajes.

\section{CARA DE PLATA, DIRIGIDA POR ETELVINO VÁZQUEZ (2002)}

Etelvino Vázquez (Lugones, Asturias, 1950) estrena Cara de plata, con Teatro I Piau y Al Suroeste, en octubre de 2002 en Narón ${ }^{4}$. El elenco lo forman trece actores que llegan a representar a los más de cuarenta personajes que tiene la obra.

La puesta en escena resulta bastante fiel al texto, si bien la división en tres jornadas que aparecía en la obra de Valle-Inclán pasa aquí a una serie de secuencias en donde apenas se refleja el mundo rural gallego de las ferias y de los conflictos entre el Pueblo, la Iglesia y la Hidalguía (Giuliani, 2003; Suárez, 2003: 40; Montero: en línea), pues todo transcurre en un sencillo escenario que bien pudiera ser de cualquier lugar del mundo con poco más que una calle, un campo y un mesón (Oliva, 2007: 158; Suárez, 2003: 40).

Al contar con poco medios técnicos para llevarla a cabo, la crítica destaca el trabajo actoral y una buena caracterización de los personajes, si bien se puede apreciar ciertos desajustes como es la caracterización de don Juan Manuel (Pedro Antonio Penco) con un traje blanco y un sombrero que recuerda más a uno de esos emigrantes triunfadores que volvían de las Américas que a un viejo Hidalgo de un pazo señorial (Barrera, 2002: 73; González, 2004: 71; Díaz-Faes, 2003: 78).

A pesar de la intención del director de alejarse del costumbrismo, la caracterización de los personajes se acerca al naturalismo, si bien en los personajes más esperpénticos se tiende a una representación expresionista (Giuliani, 2003; Oliva, 2007: 157; Paz Gago, 2012: 251). El propio Etelvino Vázquez (2011: 291), insiste en la importancia de refle-

\footnotetext{
${ }^{3}$ César Oliva (2007) analiza cuatro de estas seis representaciones: Comedias bárbaras, de Bigas Luna (2003); Cara de plata, de Ramón Simó (2005); Romance de lobos, de Ángel Facio (2005); Divinas palabras, de Gerardo Vera (2006). Paz Gago (2012) estudia, además de estas mismas, Cara de plata de Etelvino Vázquez (2002).

${ }^{4}$ Ficha artística: Autoría: Ramón María del Valle-Inclán. Dirección escénica: Etelvino Vázquez. Dirección musical: Mariano Lozano P. Escenografía: Etelvino Vázquez y Javier López de Guereñu (Txispo). Vestuario: Lupe Esteve. Música: Mariano Lozano P. Iluminación: Eduardo Cueto. Intérpretes: Pedro Antonio Penco, Rafael Núñez, Francesc Galcerán, Cristina Samaniego, Laura Orduña, Maite Jiménez, Celia Nadal, Juan Carlos Castillejo, María Ayuso, Javier Azuara, Alberto Iglesias, Carlos Domingo, Manuel Menárguez y Pietro Olivera. Estreno: 25 de octubre de 2002 en el Auditorio Municipal de Narón, A Coruña (http://teatro.es/estrenos-teatro/ cara-de-plata-23099 [20/01/2016]).
} 
jar en los personajes las pasiones humanas como es el amor entre Cara de Plata (Francesc Galcerán) y Sabelita (Cristina Samaniego), o el egoísmo de sus mayores, y en todos ellos se puede observar una actuación muy formal y académica, acorde a su vestuario simple y atemporal.

En cuanto al grupo de los personajes esperpénticos, se alejan de cualquier caracterización realista, formado principalmente por los miembros de la Iglesia encabezado por el iracundo e soberbio Abad (Rafael Núñez), acompañado de doña Jeromita y Ludovina, que en ese afán de degradarlos, acaban siendo demasiado chillonas y de sonrisa fácil (García Bañuelos, 2003: 62), y el loco Fuso Negro (Javier Azuara) que cumple muy bien su papel de loco endemoniado, a la vez que sirve de enlace entre escena y escena.

\section{LAS COMEDIAS BÁRBARAS, DIRIGIDA POR BIGAS LUNA (2003)}

La segunda representación se trata de una versión muy personal que hace de las Comedias bárbaras el cineasta Bigas Luna (Barcelona, 1946- 2013). La obra se estrena en 2003 en Valencia ${ }^{5}$, en la Nave de Sagunto de 8.000 metros cuadrados, bajo un exceso de efectos escenográficos, con un presupuesto de dos millones y medio de euros, y un elenco de cerca de 90 actores (Alsedo, 2003: 43; Francisco, 2003: 42; Máñez, 2003: 46).

La adaptación de Pablo Ley, reduce a hora y media, las siete horas aproximadas que duraría representar la trilogía, lo que ocasiona abundantes saltos y omisiones, pero sobre todo hay que destacar la visión del director, más cercano a la sensualidad mediterránea que a la Galicia atlántica que hace que los temas centrales como la transformación social o la decadencia del viejo hidalgo pierdan fuerza a favor del conflicto folletinesco entre el padre y el hijo por Sabelita (Alamillo, 2004: en línea; Máñez, 2003: 46; Oliva, 2007: 153-155).

El ambiente gallego se reduce a ciertos tópicos como que a la entrada del espectáculo se ofrezca a los asistentes queso de tetilla y orujo, o la presencia de un botafumeiro, representativo de la catedral de Santiago pero que no aparece en los textos de Valle-Inclán. Ya dentro de la representación, se recrea de forma anecdótica el paisajismo gallego con varios minutos de película rodados en Galicia, concretamente del oleaje del Atlántico contra los acantilados (Francisco, 2003: 42; Máñez, 2003: 46).

\footnotetext{
${ }^{5}$ Ficha artística: Autoría: Ramón María del Valle-Inclán. Adaptación: Pablo Ley. Dirección: Bigas Luna. Puesta en escena: Ferrán Madico. Escenografía: Manuel Zuriaga y Josep Simón. Vestuario: Francis Montesinos. Coreografía: Noelia Liñana. Música: Miguel Marín. Escultor: Miquel Navarro. Iluminación: Albert Faura. Sonido: José Luis Álvarez. Intérpretes: Juan Luis Galiardo, Sergio Peris Mencheta, Carmen del Valle, Pep Cortés, Isabel Rocatti, Empar Ferrer, Juli Salvi, Carles Sanjaime, Josep Albert Ruiz, Enric Benavent, Juli MIra, Ester Bové, Pedro Casablanc, Adán Rodríguez, Sergio Villanueva, Lola Molto, Miguel Ángel Romo, Ángel Burgos, Xoan Cejudo, Isabel Gadea, Victoria Lepori, Domenech de Guzmán, Sara Illán, Clara García, Luisa Martínez, Toni Misó, Diego Braguinski, Ferran Gadea, Empara Canet, Joan Simó, Jaime Linares, Benjamín Seva, Neus Agullo, Mari Franç, Juansa Lloret, Matías Martínez, Manuel Ochoa, Domingo Chinchilla, Álvaro Báguena, Rosita Amores y Antonio Campos. Estreno: 30 de septiembre de 2003 en la Nave de Sagunto (Valencia) durante la Bienal de Valencia (http://teatro.es/estrenos-teatro/comedias-barbaras-23675 [23/01/2016]).
} 
A pesar de las expectativas del actor protagonista, Juan Luis Galiardo, en relación con el hecho de que las dimensiones de la Nave de Sagunto no le restase cercanía con el espectador, el trabajo actoral queda eclipsado con tanta escenografía, efectos de luz y sonido, y enormes proyecciones de imágenes (Fernández-Santos, 2003: en línea; Benach, 2003: 39). A ello hay que añadir que en esta nueva versión de Bigas Luna, la caracterización de los personajes también es diferente a lo que aparecía en los textos de Valle-Inclán: don Juan Manuel destaca por su personalidad de viejo seductor, Cara de Plata (Peris Mencheta) es aquí un joven sufridor por un amor imposible, siendo incluso él, y no don Mauro, quien ejecute la muerte de don Juan Manuel, y sólo don Pedrito (Pedro Casablanc) se muestra como el ser primitivo que no domina sus instintos (Máñez, 2003: 46; Savall, 2003: 77; Oliva, 2007: 154).

\section{CARA DE PLATA, DIRIGIDA POR RAMÓN SIMÓ (2005)}

La tercera obra representada es de nuevo Cara de plata, dirigida ahora por Ramón Simó (Tarragona, 1961), con en el CDN, y estrenada el 13 de enero de 2005 en el Teatro María Guerrero de Madrid ${ }^{6}$.

La adaptación del texto se ajusta bastante al original pero sin la división en tres jornadas y con un resultado final de 16 escenas, cuyos cambios de escenario van acompañados con una música de transición que a veces se adentra en las escenas para ambientar las emociones de los personajes.

La intención del director es hacer una representación poco costumbrista, lo que se plasma en el gran despliegue de medios escenográficos que opta por una versión escenográfica muy libre, y en la que poco se puede encontrar de la Galicia mítica de Valle-Inclán. El escenario consta de un enorme muro que se abre y se cierra, dando paso a los diferentes personajes y sobre el que se proyecta diferentes imágenes, creando un ambiente que recuerda más a un wéstern americano con sus duelos y disparos que a la Galicia rural del siglo XIX (Garzón, 2005a: 56; Haro, 2005a: 37).

Para la crítica en general, la incorporación de tantas innovaciones es debido a que este director apenas tuvo contacto con este tipo de textos y ofrece una mirada más teatral que filológica (Díaz Sande, 2005: en línea). Sin embargo hay quien se muestra partidario de este tipo de adaptaciones, como es el caso de Gago Rodó para quien más que representar "el texto", se escenifican "con el texto" (Gago, 2005: 114), o de César Oliva quien defiende

\footnotetext{
${ }^{6}$ Ficha artística: Autoría: Ramón María del Valle-Inclán. Dirección: Ramón Simó. Escenografía: Christoph Schübiger. Vestuario: María Araujo. Música: Joan Alavedra. Iluminación: Quico Gutiérrez (AAI). Intérpretes: Óscar Rabadán, Miguel Zúñiga, Pablo Vázquez, Alfredo Alba, Josep Albert, Pedro G. de las Heras, Jesús Alcaide, Martxelo Rubio, Raúl Prieto, Andrés Ruiz, Santiago S. Roldán, Eduardo Mayo, Ángel Soto, Lucía Quintana, Maite Brik, Carlota Gaviño, Elena González, Jesús Noguero, Bárbara Goenaga, Chete Lera, Enrique Fernández, Pepo Oliva, Juan Codina y Susi Sánchez. Estreno: 13 de enero de 2005 en el Teatro María Guerrero de Madrid (http://teatro.es/estrenos-teatro/cara-de-plata-26000 [20/01/2016]).
} 
este tipo de innovaciones aunque haya que pagar ciertos peajes, concretamente en lo que respecta a los personajes:

En el de la interpretación la solución es mucho más difícil, porque, en sí, las Comedias Bárbaras son costumbristas, lo que no quiere decir que se trate de un costumbrismo zafio y pueril, como el de la mayoría de las zarzuelas o del teatro localista de la época (Oliva, 2007: 158).

De nuevo cobra gran importancia en la caracterización de los personajes el vestuario, en donde el color negro de los Montenegro o de la Iglesia simboliza el poder, mientras el pueblo viste otros colores como las largas capas que llevan ganaderos y chalanes, y que aparecen con paraguas bajo una fuerte tormenta que nada tiene que ver con la Galicia de Valle-Inclán (Villán, 2005b: 51; Fondevila, 2005a: 42).

Si bien el director definía esta puesta en escena como "poco costumbrista" (Villán, 2005a: en línea), no por ello deja de ser naturalista, como ocurre con los tonos que manejan los actores opuestos a los tonos agudos e histriónicos de los personajes esperpénticos del Cara de plata de Etelvino Vázquez. La crítica destaca el trabajo de los actores de tono naturalista como Chete Lera (Don Juan Manuel), Jesús Noguero (Cara de Plata) o Lucía Quintana (La Pichona), así como el papel del protagonista, si bien se muestra poco pasional y demasiado amable (Oliva, 2007: 159; Izura, 2005:79; Zabalza, 2005: 84; Ordóñez, 2005: 20; López Mozo, 2005a: en línea). Por su parte, en los campesinos apenas hay rastro de la retranca gallega, al no saber mostrar las dobleces e ironías que aparecen siempre en estas obras de Valle-Inclán, de la misma forma que las protestas de los "feriantes gallegos" quedan veladas en el exceso de gritos y carreras que abundan en la representación (Villán, 2005b: 51; Velasco, 2005: 27).

Finalmente, en cuanto al grupo de los personajes esperpénticos, formado principalmente por los miembros de la Iglesia y los bufones, su caracterización queda reducida a una vestimenta negra símbolo del poder y del oscurantismo en el caso del Abad (Pepo Oliva) o doña Jeromita (Susi Sánchez), o a la locura de un predicador iluminado en el caso de Fuso Negro (Enríquez Fernández), si bien la crítica destaca al sacristán Blas de Míguez (Juan Codina) por su papel de bufón shakesperiano (García Garzón, 2005a: 56; Ordóñez, 2005: 20; Fondevila, 2005a: 42; Zabalza, 2005: 84).

\section{ROMANCE DE LOBOS, DIRIGIDA POR ÁNGEL FACIO (2005)}

Ángel Facio (Madrid, 1938) lleva a escena Romance de lobos tras haberlo intentado años atrás, en 1983, en Polonia. La obra se estrena en marzo de 2005 en el Teatro Español de Madrid $^{7}$ con un elenco formado por 36 actores.

\footnotetext{
7 Ficha artística: Autoría: Ramón María del Valle-Inclán. Dramaturgia y dirección: Ángel Facio. Escenografía: Paco Azorín. Vestuario: Begoña del Valle-Iturriaga. Iluminación: Mario Gas y Francisco Ariza. Sonido: José Antonio Gutiérrez. Intérpretes: Manuel de Blas, Elena Sendón, Rafael Núñez, Luis Arrasa, Mahue Andúgar, Yolanda Ulloa, Rosa Álvarez, Moncho Sánchez-Diezma, Francisco Matute (Poika), José Maya, Sergio Macías, Carlos Moreno, Luisa Martínez Pazos, Trini Rugero, Juanma Navas, Román S. Gregory, Víctor Anciones,
} 
Se trata de un compleja versión textual en donde se recoge fragmentos no sólo de las Comedias sino de todas aquellas relacionadas con el ciclo mítico, como Divinas palabras o El embrujado, o incluso Ligazón, con el objetivo de que en su conjunto tenga más sentido, y consecuentemente se pueda completar la información de los personajes en una consecución de escenas que facilita la narración (López Mozo, 2005b: en línea; Perales, 2005: 37; Pulido, 2005: 12).

La estética simbolista se aprecia desde un primer momento con un escenario formado por un gran portalón metálico, alrededor del cual se simulan los diferentes espacios sobre unas placas metálicas que recuerda al paisaje gallego, desde un bosque con ánimas en pena hasta un mar muy bravo en donde se produce un naufragio (Alonso, 2005: 60). Vuelven a estar muy presentes los efectos de luz, color y sonido, que ahora proporcionan ciertos matices expresionistas a estos personajes en un principio tan realistas, y cuyo resultado final recuerda a los aguafuertes de la pintura gallega (Haro, 2005b:43; Villán, 2005c:49); y a un expresionismo muy cercano a Shakespeare:

Shakespeare es una de las principales referencias que mencionan los estudiosos cuando hablan de las Comedias Bárbaras de Valle-Inclán. Y Ángel Facio ahonda en ello. Una de sus ideas acerca del espectáculo es "subrayar el olor a Shakespeare". Romance de lobos tiene algo- quizá mucho- de Coriolano y de Rey Lear; con un desgarramiento de corte expresionista que lo acerca más a nosotros" (Bravo, 2005a: 27).

Este espacio rural influye en la caracterización de los personajes, comenzando por don Juan Manuel (Manuel de Blas), cuyo papel fue elogiado por la crítica en general (Bravo, 2005b: 53; Fondevila, 2005b: 46; García Garzón, 2005b: 69; López Mozo, 2005b: en línea). Su carácter trágico se ve reforzado por un manejo de la entonación, grave y rotunda, si bien pude resultar anacrónica en los que parece propia de actores de otros tiempos a lo que hay que sumar su "larga levita romántica" (Paz Gago, 2012: 260).

Pero donde más se hace relevante la presencia de Galicia es en la caracterización del grupo de mendigos, criados y marineros que llevan ropas campesinas y hacen uso del acento gallego, consiguiendo dar un efecto naturalista posiblemente sin proponérselo ${ }^{8}$. De entre ellos destacan don Galán (Rafael Núñez) y Fuso Negro (Fernando Sansegundo), dos personajes de aldea que hacen de bufones al estilo shakesperiano y sobre todo el Pobre de

Ricardo Vicente, Juan Viadas, Antonio M. M., Paco Maestre, Damià Barbany, Gloria Villalba, Diego Pizarro, Pepe Soto, Celia Nadal, Ricardo Solveira, Adela Armengol, Fernando Sansegundo, Resu Morales, Alfonso Delgado, Nuria Gullón, Juan Viadas, Raúl Sanz, Víctor A. Mangas, Patricia Santos, Carmela Quijano, María Piquer y Marga Escudero. Estreno: 31 de marzo de 2005 en el Teatro Español de Madrid (http://teatro.es/estrenosteatro/romance-de-lobos-26076 [23/01/2016]).

${ }^{8}$ Haro Tecglen opina que el acento gallego de algunos actores destruye el "juego idiomático" (Haro, 2005b: 43), ya que la elección de una lengua u otra debe quedar dentro de lo que es una convención teatral. Para Jerónimo López Mozo (2005b: en línea) este acento gallego no hay que verlo como un elemento naturalista, sino como un lenguaje estilizado que sale, eso sí, de las raíces de la lengua popular gallega, pero cuya función es la sonoridad global no la verosimilitud, aunque ello de como resultado, sin proponérselo, cierto "naturalismo dialectal" (Oliva, 2007: 165). Se trata por tanto de un lenguaje simbólico que se puede proyectar con un significado universal y que "no debería interpretarse en la clave naturalista" (Alba, 2007: 205). 
San Lázaro (Paco Maestre) que parece sacado de "los dibujos de Castelao" (López Mozo, 2005b: en línea).

\section{DIVINAS PALABRAS, DIRIGIDA POR GERARDO VERA (2006)}

Gerardo Vera (Madrid, 1947) lleva a escena esta obra de Valle-Inclán el 23 de febrero de 2006 al Teatro Valle-Inclán de Madrid ${ }^{9}$ con un elenco de 23 actores.

Esta representación vuelve a optar por una estilística naturalista si bien alejada del costumbrismo (Bravo, 2006: 58), que nada tiene que ver con la versión de Iniesta estrenada a finales de los noventa, totalmente expresionista y que tan buena recepción tuvo por la crítica $^{10}$.

Ahora la adaptación corre a cargo de Juan Mayorga, que realiza pocos cambios, quitando, uniendo y ordenando algún diálogo, pero sin añadir nada nuevo y siguiendo fielmente las acotaciones del autor (Hevia, 2006: 79; Ordóñez, 2006: 21; Oliva, 2007: 161; Torres, 2006:47; Vallejo, 2006: 100), con la finalidad de reflejar Galicia real de la época, sórdida pero a la vez telúrica e irreal (Bacigalupe, 2006: 73; David Carrión, 2006:36).

Valle-Inclán publica esta obra en 1920, comienzo del ciclo esperpéntico, si bien son pocos los efectos expresionistas que el director ha llevado a escena, entre los que se podrían incluir el haber dado el papel del perro Coimbra a un actor (Pietro Olivera) que se convierte en una prolongación de su dueño, realizando un difícil ejercicio gestual y corporal $^{11}$, a la vez que sirve de transición entre escenas, simbolizando el nexo entre el mundo animal y los "instintos más primitivos del hombre" (Vera, 2011: 296), la actuación ha sido calificada de "sobresaliente" (García Garzón, 2006: 62), si bien hay quien opina que una mejor

\footnotetext{
${ }^{9}$ Ficha artística: Autoría: Ramón María del Valle-Inclán. Versión: Juan Mayorga. Dirección: Gerardo Vera. Escenografía: Ricardo Sánchez Cuerda y Gerardo Vera. Vestuario: Alejandro Andújar. Música: Luis Delgado. Iluminación: Juan Gómez-Cornejo (A.A.I). Sonido: Mariano López. Movimiento escénico: María del Mar Navarro. Diseño vídeo: Álvaro Luna. Intérpretes: Fidel Almansa, Ester Bellver, Sonsoles Benedicto, Míriam Cano, Paco Déniz, Charo Gallego, Gabriel Garbisu, Carlota Gaviño, Emilio Gavira, Elisabet Gelabert, Elena González, Alicia Hermida, Daniel Holguín, Javier Lara, Jesús Noguero, Pietro Olivera, Idoia Ruiz de Lara, Sergio Sánchez, Fernando Sansegundo, Julieta Serrano, Julia Trujillo, Pablo Vázquez y Abel Vitón. Estreno: 23 de febrero de 2006 en el Teatro Valle-Inclán de Madrid (http://teatro.es/estrenos-teatro/divinas-palabras-27869 [20/01/2016]).

${ }^{10}$ La dirigida por Ricardo Iniesta (2009) se trata de una reposición de la misma obra dirigida en 1998. El texto se respeta al máximo. Una nueva versión que acaba por convencer a la crítica y al público, que incluso la han calificado de "Valle en estado puro" (Paz Gago, 2012: 177), y ha recibido grandes elogios de críticos como Hormigón y Vieites. Manuel Vietes (2011) propone que las obras deben de ser antinaturales, buscando una unión entre la escenificación y el lenguaje; también Hormigón pone en relieve la importancia de las palabras no sólo por lo que significan sino el habla, y en concreto en Valle-Inclán cuyo teatro no tiene nada de naturalista ni de psicologista, ya que los personajes son "construcciones formales", piezas dentro de un grupo coral (Hormigón, 2011: 258)

${ }^{11}$ Hay que recordar en este punto la dificultad de estas escenas con el perro Coimbra y de otras como el Trasgo Cabrío, que incluso para el cine y a pesar de contar con muchos más recursos, se opta a veces por eliminar este tipo de escenas (Ochando, 2002: 453).
} 
opción hubiese sido utilizar un perro domesticado (Cardona, 2011: 265). Otra variación que aleja esta puesta del naturalismo, es el clima coral presente en toda la obra ya desde el inicio en que los actores pasean por el escenario antes de comenzar con la representación propiamente dicha (Oliva, 2007: 162).

La escenografía de Sánchez Cuerda lo constituye una pared y un árbol, un escenario sencillo pero que logra evocar el salvajismo propio de la Galicia medieval que seguía presente a principios del siglo XX (Intxausti, 2006: 50; Hevia, 2006: 79; Ordóñez, 2006: 21).

Los personajes se mueven dentro de ese mundo rural y cerrado sin la exagerada "ampulosidad" que el propio Valle-Inclán criticaba en algunos actores cuando fue estrenada esta obra en 1933 (Villán: 2006:44), deformación en la caracterización de los personajes que sigue siendo tema de debate para los estudiosos del teatro de Valle-Inclán:

[...] la estética valleinclaniana (...) propone amplificación deformadora de los personajes para desvelar sus comportamientos, en este caso en el territorio literario dramático. Cuestión diferente sería plantearnos cómo debe interpretarse esto desde el punto de vista escénico y de qué modo lo podríamos abordar; si esta amplificación deformante que aparece en el plano literariodramático debemos proseguirla en la representación. Personalmente tengo en este momento notables dudas de que deba hacerse (Hormigón, 2003: 74).

Entre estos personajes destaca Mari-Gaila, representado por Elisabet Gelabert, caracterizado como una mujer muy viva si bien demasiado bella para ser la mujer de un sacristán de pueblo (Orlando, 2010: en línea; Oliva, 2007: 163) que se va transformando en un ser desvalido y resignado como muestra el desnudo final de la obra (Paz Gago, 2009: 142). Por su parte, su marido, Pedro Gailo (Fernando Sansegundo), aparece caracterizado como un clérigo de aldea cuya imagen se va deformando en sombras, reflejo de su carácter turbio y atormentado (Ordóñez, 2006: 21).

Esta caracterización entre naturalista y simbolista obtiene buenos resultados para la crítica que elogia en buen trabajo de los actores tanto por su actuación como por su caracterización (García Garzón, 2006: 62; Vallejo, 2006: 100; Ordóñez, 2006: 21)

\section{COMEDIAS BÁRBARAS. MONTENEGRO, DIRIGIDA POR ERNESTO CABALLERO (2013)}

La última puesta en escena de las Comedias bárbaras es la dirigida por Ernesto Caballero (Madrid, 1958), con el título de Montenegro con el CDN, en noviembre de 2013, en el Teatro Valle-Inclán de Madrid ${ }^{12}$ con un elenco de 21 actores, con dobles y triples papeles, y algo más de tres horas de duración.

\footnotetext{
${ }^{12}$ Ficha artística: Autoría: Ramón María del Valle-Inclán. Versión: Ernesto Caballero. Dirección escénica: Ernesto Caballero. Escenografía: José Luis Raymond. Vestuario y caracterización: Rosa García Andújar. Música y sonido: Javier Coble. Iluminación y vídeo: Valentín Álvarez. Intérpretes: Fran Antón, Ramón Barea, Ester Bellver, David Boceta, Javier Carramiñana, Bruno Ciordia, Paco Déniz, Silvia Espigado, Marta Gómez, Carmen León,
} 
Se trata de una versión adaptada que arranca en Romance de lobos para luego representar, como si de un recuerdo se tratase, escenas de Cara de plata y Águila de blasón, con una selección final que no siempre consigue mostrar un desarrollo fluido de la acción y de ritmo (Ordóñez, 2014: 18; Gabaldón, 2013: en línea). Por otra parte, en esta adaptación no se sigue los textos de una forma literal sino que crea un lenguaje específicamente teatral tanto en los diálogos como en las acotaciones, en las que para la crítica se evoca esa Galicia mítica de Valle-Inclán pero con un tratamiento alejado del naturalismo (Díaz Sande, 2013: en línea; Fernández, 2014: en línea).

Ernesto Caballero reconoce que, tras unas conversaciones con Doménech ${ }^{13}$, se decanta por la visión simbolista de la obra pero con cierto "color local" (Ayans, 2013a: 74; Vidal-Folch, 2014:5). Para ello se ha recurrido a la escenografía de José Luis Raymond, formada por un puente de piedra, símbolo del paso de una sociedad estamental a otra más moderna, en donde las nuevas tecnologías vuelven a estar presentes para evocar ese mundo mítico creado por Valle-Inclán, a lo que hay que añadir el trabajo actoral gracias al cual se va formando figuras de animales y objetos (López Mozo, 2013: en línea; Ayanz, 2013b: 83; Cabrera, 2014: en línea).

El simbolismo también está presente en la caracterización de los personajes en los que se puede observar dos grupos claramente diferenciados. El primero está formado por aquellos personajes cuya vestimenta "neandertal" simboliza las pasiones e instintos más básicos entre los que destacan Ramón Barea (don Juan Manuel) cuyo papel ha sido elogiado por la crítica a pesar de su extensión y de la falta del pathos intrínseca en este personaje (Muñoz, 2013: en línea; Fernández, 2014: en línea; Catalán, 2013: en línea; Vallejo, 2013: 36). Otro personaje que destaca en este grupo de instintos primitivos es don Galán (Janfri Topera), el criado de la Galicia profunda que se asemeja por su inteligencia y sinceridad al bufón shakesperiano (Galán, 2014: en línea; Villán, 2013: 37; Ayans, 2013b: 83).

El segundo grupo de personajes lo constituyen campesinos y personajes cercanos a la familia Montenegro, entre los que destacan las mujeres, doña María (Yolanda Ulloa) en su papel de mujer convencional, Sabelita (Rebeca Matellán) una joven ingenua y llena de contradicciones, la vieja criada la Roja (Mona Martínez), y la joven Pichona (Ester Bellver), campesina sensual e impúdica pero a la vez encantadora. Todos ellos muy elogiados por la crítica (Catalán, 2013: en línea; Díaz Sande, 2013: en línea; Doria, 2014: en línea; Ojeda, 2013: 39; Ordóñez, 2014: 18; Otheguy, 2013: en línea).

A estos dos grupos habría que añadir un tercer grupo de personajes esperpénticos, entre los que destacan los miembros de la Iglesia vestidos de negro como es el caso del cruel y prepotente Abad (Alfonso Torregrosa), o el loco de aldea Fuso Negro (Edu Soto) personaje

Toni Márquez, Mona Martínez, Rebeca Matellán, Iñaki Rikarte, José Luis Sendarrubias, Edu Soto, Juan Carlos Talavera, Janfri Topera, Alfonso Torregrosa, Yolanda Ulloa y Pepa Zaragoza. Intérpretes-músicos: Javier Coble y Kepa Osés. Estreno: 29 de noviembre de 2013 en el Teatro Valle-Inclán de Madrid (http://teatro.es/estrenosteatro/montenegro-comedias-barbaras-61863 [24/01/2016]).

${ }^{13}$ Doménech (2008) compara este teatro de Valle-Inclán con el teatro denominado rural de García Lorca a los califica de simbolistas. Lo mismo hacen Huerta Calvo y Peral Vega en el capítulo titulado "Valle-Inclán", en Historia del Teatro Español, Tomo II, dirigido por Huerta Calvo. 
bufonesco de clara influencia shakesperiana pero cuyo raro atuendo le da más aire de gracioso que de siniestro (Olaya, 2013: en línea).

\section{CONCLUSIONES}

En líneas generales se puede concluir que en estas puestas de escena la presencia de Galicia ha sido gradual, de unas primeras representaciones en donde hay un claro alejamiento de todo lo referido a elementos gallegos en escenarios y ambientes, a las ultimas donde se opta por una estética entre simbolista y expresionista que evoca una Galicia más acorde a la que Valle-Inclán recreaba en sus textos, y en donde la crítica se ha mostrado más unánime es sus valoraciones positivas.

En la primera representación de Cara de plata, dirigida por Etelvino Vázquez (2002), los pocos recursos con los que cuenta para su puesta en escena así como la opción naturalista no logra evocar ese espacio mágico y primitivo del que Valle-Inclán se sirve para criticar una Galicia atrasada y sumisa. El espacio podría ser cualquier aldea con sus caminos, su casas y el espacio abierto del mundo rural, lo que provoca algunos desfases en la caracterización de los personajes, como es el caso de don Juan Manuel que aparece vestido como rico emigrante en vez de un hidalgo que administra su pazo gallego.

Un año más tarde se representan las Comedias dirigidas por Bigas Luna (2003), una versión libre más que una adaptación, en la que la presencia de la Galicia de Valle-Inclán se reduce para la crítica a ciertos tópicos y alguna breve sugerencia al paisaje atlántico. Ello hace que la historia sea otra, protagonizada ahora por el romance entre dos jóvenes enamorados, y en la que don Juan Manuel en vez de evocar el final de la sociedad feudal del mundo gallego parece mostrar más bien al decaimiento del macho ibérico.

Con la tercera representación, que vuelve a ser Cara de plata esta vez dirigida por Ramón Simó (2005), también se opta por una versión libre de los textos de Valle-Inclán, que para la crítica en general recuerda a un wéstern americano en donde los personajes sobreactúan entre gritos y peleas, y llevan paraguas bajo la lluvia. La trama se vuelve a centrar sobre los amoríos de Cara de plata y los personajes esperpénticos no logran recoger la crítica al poder de la Iglesia o la sumisión de los campesinos a pesar del buen trabajo actoral.

Pero será este mismo año, con la puesta en escena de Romance de lobos de Ángel Facio (2005), en donde encontremos la evocación más directa a esa Galicia mítica de Valle-Inclán. Se trata de una escenificación en la que su director ha optado por una visión simbolista tanto en la escenografía como en la caracterización de los personajes, y cuyo resultado final ha sido valorado positivamente por la crítica. Los diferentes escenarios logran recrear el mundo rural y marinero con toda su fuerza y violencia, evocando una tormenta en el bosque o las olas bravas del mar, en una ambiente muy shakesperiano y acorde a la caracterización de unos personajes que se mueven más por instintos que por la razón, y en donde el despotismo de la familia Hidalguía y de la Iglesia logra dominar a los sumisos campesinos.

Otra puesta en escena, calificada por la crítica entre naturalista y simbolista, es Divinas palabras dirigida por Gerardo Vera (2006), en la que se ha valorado tanto su influencia sha- 
kesperiana como su fidelidad al texto a pesar de ciertas licencias como la de que sea un actor quien represente el papel de un perro. El escenario, si bien parece sencillo y sin grandes excedencias de medios audiovisuales, logra evocar el ambiente de penuria y crueldad de esta sociedad cerrada y rural donde tiene especial importancia lo mágico y lo onírico, concretamente el mundo de las apariciones. Los personajes están caracterizados por su crueldad y falta de solidaridad en una obra, publicada en 1920 en donde Valle-Inclán tendía cada vez más por la crítica social.

Finalmente en Montenegro de Ernesto Caballero (2013), la escenografía vuelve a evocar, como en la obra de Ángel Facio, un espacio gallego de bosques, tormentas y naufragios gracias a medios audiovisuales, a lo que hay que añadir el trabajo actoral creando un mundo de figuras y animales que ayuda a mostrar ese mundo mítico de Valle-Inclán. El escenario simbólico lo forma principalmente un puente, que evoca el paso de la sociedad feudal a la nueva sociedad burguesa, pero también la evolución psicológica del protagonista, de un hombre soberbio y prepotente a la locura y soledad del final. La crítica elogia esta puesta en escena donde se representa la fuerza de la Naturaleza en simbiosis con la violencia de los personajes, algunos de ellos vestidos como hombres del Neandertal, símbolo de sus instintos más primitivos, o del negro de los miembros de la Iglesia que evoca su poder.

\section{REFERENCIAS BIBLIOGRÁFICAS}

Alamillo García, M.J. (2004). "Nos faltó la voz y la palabra (Sobre la adaptación de las Comedias bárbaras de Bigas Luna)”. El pasajero. Invierno. En línea: http://www.elpasajero.com/tablado/ bigaslunacronica.html [20/09/2015].

Alba Peinado, C. (2007). "Motivos y estrategias en Romance de lobos: el aullido de la independencia”. En Análisis y espectáculos teatrales (2000- 2006), J. Romera Castillo (ed.), 195- 208. Madrid: Visor Libros.

Alonso, J. (2005) "Una propuesta convincente", El Mundo. Guía del ocio, 30 de marzo, 12.

Alsedo, Q. (2003), "Bigas Luna adapta en clave circense las Comedias Bárbaras", El Mundo, Nacional, 6 de septiembre, 43.

Ayans, M. (2013a). "Bárbaro: Montenegro llega al CDN". La Razón, 29 de noviembre, 74-75.

- (20г3в). "Montenegro (Comedias bárbaras). Aullidos wagnerianos". La Razón, 6 de diciembre, 83.

Bacigalupe, C. (2006), "El grito y el ámbito", El Mundo (Cultura), 30 de abril, 73.

Barrera, L. (2002). "Al Suroeste estrena una comedia bárbara de Valle". El Periódico, 18 de octubre, 73.

BenaCH, J.-A. (2003). "Valle-Inclán y Bigas Luna, bárbaro binomio". La Vanguardia, 2 de octubre, 39.

Bravo, J. (2005a). "Mítica, bárbara, húmeda”, $A B C$ (Madrid), 25 de marzo, 26, 27.

- (2005B). "Ángel Facio rompe un largo silencio con la dirección de Romance de lobos". ABC (Madrid), 30 de marzo, 53.

- (2006). "Gerardo Vera apuesta por un Valle-Inclán naturalista en su montaje de Divinas palabras". $A B C, 23$ de febrero, 58. También en línea: http://www.abc.es/hemeroteca/historico-23-02-2006/ abc/Espectaculos/gerardo-vera-apuesta-por-un-valle-inclan-naturalista-en-su-montaje-de-divinas-palabras_142480049874.html\# [20/09/2015].

Cabrera, A. (2014). "Crítica de Montenegro (Comedias Bárbaras)". Masteatro, 6 de enero. En línea: http://www.masteatro.com/critica-de-montenegro-comedias-barbaras/ [20/09/2015]. 
CARdona, R. (2011). "Valle-Inclán, del teatro a la puesta en escena"-ADE-Teatro. Revista de la Asociación de Directores de Escena de España 137, octubre, 261- 269.

Catalán Deus, J. (2013). "Sobredosis de comedias bárbaras". Guía Cultural. Comunidad de Madrid, 4 de diciembre. En línea: http://www.periodistadigital.com/guiacultural/ocio-y-cultura/2013/12/04/sobredosis-de-comedias-barbaras-montenegro-valle-inclan-teatro.shtml [20/09/2015].

David Carrión, C. (2006), “Divinas palabras: un montaje desnudo”, La Razón, 24 de febrero, 36.

Díaz-Faes, F. (2003). "La Cara de plata de Valle-Inclán". La Nueva España (Oviedo), 14 de junio, 78.

Díaz SAnde, J. M. (2005). "La tercera de las Comedias Bárbaras de Ramón María de Valle Inclán sube al María Guerrero (Centro Dramático Nacional)". En línea: http://www.madridteatro.eu/teatr/ entrevistas/entrevista024.htm [20/09/2015].

- (2013). "Montenegro (Comedias bárbaras). Fuerzas primarias". Madridteatro, 3 de diciembre. En línea: http://www.madridteatro.net/index.php?option=com_content\&view=article \&id=3385:montenegro-comedias-babaras-cdn-entrevista \&catid=261:entre2013\&Itemid=236 [20/09/2015].

Domenech, R, (2008). García Lorca y la tragedia española, Madrid, Fundamentos.

Doria, S. (2014). "El rey Lear de Valle-Inclán". ABC, 24 de octubre. En línea: http://www.teatral.net/ ca/critiques/2014/10/22/montenegro-comedias-barbaras.html [20/09/2015].

FERnÁNDEZ, I. (2014). "El cacique del esperpento". Elperiódico.com, 15 de octubre. En línea: http:// www.elperiodico.com/es/noticias/ocio-y-cultura/estreno-tnc-montenegro-comedias-barbaras-3601952 [20/09/2015].

Fernández-Santos, E. (2003). "Bigas Luna reinventa las Comedias bárbaras". El País, 20 de agosto. En línea: http://elpais.com/diario/2003/08/26/revistaverano/1061848801_850215.html [20/09/2015].

Fondevila, S. (2005a). "El difícil camino de Valle-Inclán”. La Vanguardia, 15 de enero, 42.

- (2005B). "Un soberbio Valle-Inclán". La Vanguardia, 2 de abril, 46.

Francisco, I. (2003), "Brutalidad ibérica", El Mundo (El Cultural), 25 de septiembre, 42.

Gabaldón, M. (2013). “Montenegro. Teatro Valle-Inclán. Madrid”. Notodo.com, 10 de diciembre. En línea: http://www.notodo.com/escena/5401_montenegro_teatro_valleincln_madrid.html [20/09/2015].

Gago Rodó, A. (2005). "En torno a Cara de plata. Representar con Valle-Inclán”. Primer Acto 309, 109- 114.

GaLán, J. C. (2014). "Las Comedias bárbaras de Valle-Inclán: Montenegro". Elblogdejcgc, 2 de enero. En línea: http://elblogdejcgc.blogspot.com.es/2014/01/las-comedias-barbaras-de-valleinclan.html [20/09/2015].

García Bañuelos, J. C. (2003). “Cara de plata, decepción y aburrimiento”. Diario de Burgos, 23 de marzo, 62.

García Garzón, J. I. (2005a). "Valle y sus máscaras". $A B C, 24$ de enero, 56.

- (2005B). "El ocaso de los dioses". ABC, 9 de abril, 69.

- (2006). "Principio de viaje". $A B C, 28$ de febrero, 62.

Giuliani, L. (2003) "La Galicia de Valle: El poder es el diablo", Hoy Extremadura, 18 de febrero.

GonzÁlez Soler, J. (2004), "Sobre todo, Valle-Inclán”. La Opinión, 18 de febrero, 71.

Haro Tecglen, E. (2005a). "Cara de plata. Curas, putas, escopetas, vino”. El País, 17 de enero, 37.

- (2005B). "Romance de lobos. Un texto extraordinario". El País, 5 de abril, 43.

Hevia, E. (2006). “Gerardo Vera explora el lado más salvaje de Valle-Inclán”. El Periódico, 5 de julio, 79.

Hormigón, J. A. (2003). "El teatro de Valle-Inclán en el contexto europeo". Revista Cuadrante (Vilanova de Arousa, Pontevedra), 5, xaneiro, 61-78.

- (20 I I). "Escenificar a Valle-Inclán: el estado d ela cuestión”. ADE-Teatro 137, octubre, 254-260. 
Huerta Calvo, J Y Peral Vega, E, (2003) "Valle-Inclán”, en Historia del Teatro Español, Tomo II, Madrid, Gredos, 2311- 2364.

IntXausti, A. (2006). "El teatro apasiona y asusta porque envenena". El País, 26 de febrero, p. 50 (Centro de Documentación Teatral).

Izura, P. (2005). "Escenografía fundamental, interpretación desigual". Diario de Navarra, 28 de febrero, 79.

López Mozo, J. (2005a). “Cara de plata. El desafío de representar a Valle”. madridteatro.eu 21 enero. En línea: http://www.madridteatro.eu/teatr/teatro/teatro069.htm [20/09/2015].

- (2005B). “Romance de lobos. Alegoría de la España náufraga”. Madridteatro. En línea: http:// www.madridteatro.net/teatr/teatro/teatro109.htm [20/09/2015].

- (2013). "Montenegro (Comedias bárbaras)". Madridteatro, 12 de diciembre. En línea: http://www. madridteatro.net/index.php?option=com_content \&view $=$ article \&id=3397: montenegro-las-comedias-barbaras-critica\&catid=262: crit2013\&Itemid $=237$ [20/09/2015].

MáñEz, J. (2003). "Bigas Luna debuta en el teatro con unas lujosas Comedias bárbaras". El País, 30 de septiembre, 46. También en línea: http://elpais.com/diario/2003/09/30/espectaculos/1064872804_850215.html[20/09/2015].

Montero, C. "Cara de plata o la estética del primitivismo gallego" En línea: http://www.lacallemayor. net/dyn/cultura/teatro-y-danza/criticas-de-teatro/?action $=$ WzIxNztbMTI7W25hbWU7ZGVtdWVzdHJhYXJ0aWN1bG87XV1d\&217_demuestraarticulo_0_12=152

MuÑoz DíEz, L. (2013). "Montenegro, comedias bárbaras de Valle-Inclán: un espectáculo gozoso de Ernesto Caballero". Revista Tarántula, 15 de diciembre. En línea: http://revistatarantula.com/ montenegro-comedias-barbaras-de-valle-inclan-un-espectaculo-gozoso-de-ernesto-caballero/ [20/09/2015].

Ochando Madrigal, E. (2002). "Valle-Inclán y el teatro nuevo". En Del teatro al cine y la televisión en la segunda mitad del siglo XX, J. Romera Castillo (ed.), 447-454. Madrid: Visor Libros.

OJEDA, A. (2013). "Vuelve el bárbaro Valle-Inclán". El Cultural, 29 de noviembre, 39.

Olaya Pérez, F. (2013). "Montenegro de Ernesto Caballero". Blog Mitemporadateatral, 21 de diciembre. En línea: http://mitemporadateatral.blogspot.com.es/2013/12/montenegro-de-ernesto-caballero.html [20/09/2015].

Oliva, C. (2007). "Valle-Inclán en la escena institucional del siglo XXI". En Análisis y espectáculos teatrales (2000- 2006), J. Romera Castillo (ed.), 151- 167. Madrid: Visor Libros.

Ordóñez, M. (2005). "La guerra en Lantañón Contry". El País, Babelia, 12 de febrero, 20.

- (2006). "Valle encuentra piso". El País, Babelia, 8 de abril, 21. También en línea: http://elpais.com/ diario/2006/04/08/babelia/1144451177_850215.html [20/09/2015].

- (2014). "Montenegro y familia". El País, Babelia, 11 de enero, 18. También en línea: http://cultura.elpais.com/cultura/2014/01/07/actualidad/1389116442_692711.html [20/09/2015].

Orlando Rodríguez, A. (2010). "Divinas palabras, divino teatro". Artefactus Cultural Project (ACP), 16 de julio. En línea: http://artefactusteatro.org/2010/07/16/divinas-palabras-divino-teatro/ [20/09/2015].

Otheguy Rivera, H. (2013). "Montenegro: intrépida versión de las Comedias bárbaras". Culturamas, 4 de diciembre. En línea: http://www.culturamas.es/blog/2013/12/04/montenegro-intrepida-version-de-las-comedias-barbaras/ [20/09/2015].

Paz GaGo, J. M. (2000). "Valle-Inclán y el teatro gallego". Signa. Revista de la Asociación Española de Semiótica 9, 163-179.

- (2009). "Perversa y sensual. Mari-Gaila en los escenarios de los siglos XX y XXI". En El personaje teatral: la mujer en las dramaturgias masculinas en los inicios del siglo XXI, J. Romera Castillo (ed.), 129-143. Madrid: Visor Libros.

- (2012). La revolución espectacular. El teatro de Valle-Inclán en la escena mundial. Madrid: Cas- 
talia.

Perales, L. (2005), “Ángel Facio: Valle-Inclán escribe para el cine desde el teatro”, El Mundo (El Cultural), 17 de marzo, 37.

Pulido, B. (2005), "La puerta de la decadencia”, El Mundo, 30 de marzo, 12.

Romera Castillo, J. (ed.) (2002). Del teatro al cine y la televisión en la segunda mitad del siglo XX. Madrid: Visor Libros.

- (2007). Análisis y espectáculos teatrales (2000- 2006). Madrid: Visor Libros.

- (2009). El personaje teatral: la mujer en las dramaturgias masculinas en los inicios del siglo XXI. Madrid: Visor Libros.

Ruiz Ramón, F. (2001). Historia del teatro español. Siglo XX. Madrid: Cátedra (12. a ed.), 93-140.

Savall, C. (2003). "Bigas exprime a Valle-Inclán con unas comedias muy bárbaras". El Periódico, 1 de octubre, 76, 77. También en línea: http://www.elperiodicodearagon.com/noticias/escenarios/ bigas-exprime-valle-inclan-comedias-barbaras_79082.html [20/09/2015].

SuÁrez, R. (2003). “Cara de plata muestra en León el rostro de la Galicia profunda”. Diario de León, 23 de octubre, 40. También en línea: http://www.diariodeleon.es/noticias/cultura/cara-plata-muestra-leon-rostro-galicia-profunda_104327.html [20/09/2015].

Torres, R. (2006). "La universal Divinas palabras inaugura el teatro Valle-Inclán”. El País, 23 de febrero, 47.

Vallejo, J. (2006). "Había una deuda”. El País, 24 de febrero, 100.

- (2013). "Desde el umbral de dos épocas". El País, 2 de diciembre, 36.

VÁzQuez, E. (2011). "Un mundo en transformación. Cara de plata". ADE-Teatro. Revista de la asociación de directores de escena de España 137, octubre, 291.

Velasco, M. A. (2005). "A grito limpio". ABC, 10 de febrero, 27.

VERA, G. (2011), "Nuestro montaje de Divinas palabras", ADE, Revista de la asociación de directores de escena de España 137, octubre, 296, 297.

Vidal-Folch, I. (2014). "Bienvenida a las Comedias bárbaras". El País, edición de Cataluña, 19 de septiembre, 5 .

VIEITES, M. (2011). "Estética e ideología en Valle-Inclán”. ADE-Teatro 137, octubre, 94-104.

Villán, J. (2005a). "Más luz sobre Valle Inclán”. El Cultural, 13 de enero. En línea: http://www.elcultural.com/revista/teatro/Mas-luz-sobre-Valle-Inclan/11144 [20/09/2015].

- (2005в). "Sorprendente fiasco". El Mundo, 15 de enero, 51.

- (2005C). "Montenegro reaccionario, bárbaro y trágico". El Mundo, 5 de abril, 49.

- (2006). "Valle, el inaugurador". El Cultural, 16 de febrero, 44.

- (20I3). "La grandeza de Valle, cada vez más cerca". El Mundo, 2 de diciembre, 37.

Zabalza, P. (2005). "El salvaje noroeste”. Diario de Noticias, 1 de mayo, 84. 
